\title{
Effects of Sahaj Samadhi meditation on heart rate variability and depressive symptoms in patients with late-life depression - RETRACTION
}

Emily Ionson, Jayneel Limbachia, Soham Rej, Klajdi Puka, Ronnie I. Newman, Stephen Wetmore, Amer M. Burhan and Akshya Vasudev

\section{Copyright and usage}

(c) The Royal College of Psychiatrists 2021.

https://doi.org/10.1192/bjp.2018.265, Published by Cambridge University Press, 28 November 2018.

We, the Editors of BJPsych, have retracted the following article: Effects of Sahaj Samadhi meditation on heart rate variability and depressive symptoms in patients with late-life depression, Ionson, E., Limbachia, J., Rej, S., Puka, K., Newman, R. I., Wetmore, S., Burhan, A. M. and Vasudev, A, The British Journal of Psychiatry (2019), Cambridge University Press, 214(4), pp. 218-224. DOI: https://doi.org/10.1192/bjp.2018.265

A preliminary analysis of results from this study was previously published in BJPsych Open. The preliminary analysis is not specified in the trial protocol.
Preliminary analysis from the trial is also cited as prior evidence from the literature in the introduction (SSM may have a beneficial effect on depression symptoms as well as HRV12).

Additionally, the trial protocol (NCT02149810) states that the secondary outcome measures will be assessed at weeks $0,4,8,12$, and 24. However, assessments at week 24 were offered to the intervention arm and not the control arm.

\section{Reference}

Ionson, E., Limbachia, J., Rej, S., Puka, K., Newman, R., Wetmore, S, Burhan, A. and Vasudev, A. (2019). Effects of Sahaj Samadhi meditation on heart rate variability and depressive symptoms in patients with late-life depression. The British Journal of Psychiatry, 214(4), 218-224. doi:10.1192/bjp.2018.265. 